\title{
Remote monitoring of COVID-19 patients using home pulse oximetry and virtual platform: an observational study
}

\author{
AKM Akhtaruzzaman ${ }^{1}$, Md Mostafa Kamal ${ }^{2}$, Monira Parveen ${ }^{3}$, Marziur Rabbi ${ }^{4}$, Rajib Dhali ${ }^{4}$, \\ Md Shafiqul Islam ${ }^{5}$, Dilip Kumar Bhowmick ${ }^{5}$
}

Author affiliation:

1. Professor and Chairman, Department of Anesthesia, Analgesia and Intensive Care Medicine, Bangabandhu Sheikh Mujib Medical University, Shahbag, Dhaka-1000, Bangladesh.

2. Anaesthesiologist, Shaheed Suhrawardy Medical College and Hospital, Sher-E-Bangla Nagar, Dhaka-1207, Bangladesh.

3. Lecturer, Department of Pharmacology, Dhaka Dental College, Dhaka, Bangladesh.

4. Resident, Department of Anesthesia, Analgesia and Intensive Care Medicine, Bangabandhu Sheikh Mujib Medical University, Shahbag, Dhaka-1000, Bangladesh.

5. Associate professor, Department of Anesthesia, Analgesia and Intensive Care Medicine, Bangabandhu Sheikh Mujib Medical University, Shahbag, Dhaka-1000 Bangladesh.

Correspondence: Dr AKM Akhtaruzzaman, E-mail: akm.akhtaruzzaman@bsmmu.edu.bd; ORCID ID: 0000-0002-2427-1863

\section{Abstract}

Background: The coronavirus disease (COVID-19) is a global health problem with ever-increasing attributed deaths. Patients with COVID-19 may deteriorate rapidly, and their continuous monitoring is necessary. Monitoring and providing care beyond the traditional face-to-face model is a new chapter in the history of medicine. It consists of remote monitoring and management using virtual platform as a critical component in the ever-changing environment of this deadly pandemic. We evaluated the impact of remote monitoring of the patients at their residences after being infected with SARS-COV-2 virtually.

Methodology: This observational study was conducted among patients with symptoms of COVID-19 attending in the Fever Clinic between January and March 2021. The study was set to continue for the duration of the pandemic. Access to pulse oximeter and virtual platform was given to the enrolled patients. The participants were monitored in a remote monitoring platform at home and during the hospital stay. The primary outcome measures included number of recovery i.e. discharged from remote home monitoring and/or hospital and escalation of management such as hospitalization or transfer to the ICU facilities. Duration of hospital stay, patient experience and satisfaction, and barriers to use the virtual platform were included in the secondary outcome measures.

Results: A total of twenty patients (median age $45 \mathrm{y}$, male to female ratio 65:35) were included. The median duration of monitoring was 10 days (IQR 8-12 days). Out of twenty patients, 3 (15\%) patients needed hospitalization and were recognized in time by the team. The duration of hospital stay was 4 days median (IQR 3-6 days). All patients were discharged from this service safely; no death was reported. Ninety percent of the studied population were satisfied and felt reassured by this remote monitoring service.

Conclusion: Early recognition of deterioration and prompt management through remote monitoring model increases the chances of survival of patients, and reduces the morbidity. Such remote monitoring model can be applied for future outbreaks of pandemics.

Key words: COVID-19; Remote monitoring; Pulse oximetry; Emerging technologies; Virtual platform; Likert's scale; Satisfaction. 
Citation: Akhtaruzzaman AKM, Kamal MM, Parveen M, Rabbi M, Dhali R, Islam MS, Bhowmick DK Remote monitoring of COVID-19 patient using home pulse oximetry and virtual platform: an observational study. Anaesth. pain intensive care 2022;26(1):89-95. DOI: 10.35975/apic.v26i1.1773

Received: December 14, 2021, Reviewed: January 16, 2022, Accepted: January 22, 2022

\section{Introduction}

The world has been struggling with the pandemic caused by the frequently mutated SARS-CoV-2 virus globally, which was first reported in China in December 2019., Overwhelmed health facilities, $\left.{ }^{3}\right]$ resulted in closure of nonessential services, schools, travelling restrictions and recursive national lockdowns. ${ }^{4}$ As of November 25, 2021 , there were about $260,177,573$ people infected with SARS COV-2 and 5,197,677 deaths worldwide. ${ }^{5}$

COVID-19 presents with a wide range of clinical spectrum. Among them hypoxia and hypoxic respiratory failure were independently associated with high risk of in-hospital mortality. ${ }^{6,7}$ Initially COVID-19 may present with no symptoms at all, and sometimes with silent hypoxia, ${ }^{8}$ which may lead to pneumonia followed by acute respiratory distress syndrome. ${ }^{9}$ Delayed presentation due to silent hypoxia results in admission to hospitals with an advanced course of the disease, requiring prolonged hospital stay, invasive treatment, admission to intensive care units and death. ${ }^{10}$ This situation has posed a big challenge to healthcare resource allocation and management especially in lower and lowmiddle income countries. Currently Bangladesh has a total of 11,428 general hospital beds and 556 ICU beds reserved for COVID- 19 patients. According to WHO report in November 2020, 25.5\% general and 53.9\% ICU beds were occupied. ${ }^{11}$ Even before the COVID-19 era only 3.05 physicians and 1.07 nurses were available for 10000 people on an average in Bangladesh. ${ }^{12}$ With these limited resources Bangladesh has been tackling COVID19 , where $20 \%$ infected cases need hospital admission, and out of them $12 \%$ need ICU facilities. ${ }^{13}$ A recent study in an ICU of Bangladesh showed high case fatality rate of about $77.6 \%$ because of late reporting and multiple comorbidities. ${ }^{14}$

For effective monitoring and follow up, modern technologies played a pivotal role to produce relevant policies, implementation of rational guidelines and constantly measure the responses in such a dire outbreak. These technologies improved management, emphasizing the rational use of resources, incident-based monitoring system, and formulation of new drugs and vaccines. ${ }^{15}$ High-tech technologies such as AI (artificial intelligence), industry 4.0, IoT, Internet of Medical Things (IoMT), big data, virtual reality (VR), drone technology, autonomous robots, 5G technology, and block chain were used for the analysis of COVID-19 patients. ${ }^{16,17}$ Diverse software and numeral steering tailored to handle these technologies for smooth and effective healthcare disposition are accessible at present. ${ }^{18}$ These can be used for prompt diagnosis of worsening of COVID-19 patients being treated at home. ${ }^{19,} 20$ Remote home monitoring provides more detail on clinical assessment like severity, and duration of COVID-19 symptoms, evaluation of other symptoms, co-morbidities and social situation, arrangements of follow-up, and prioritizing extremely vulnerable cases. ${ }^{21}$

Despite previous research on the use of remote home monitoring models during the COVID-19 pandemic, studies on their impact on patient outcome are rare. Thus, using home pulse oximetry and virtual observations of its impacts as an important tool was the prime objective of our study.

\section{Methodology}

This observational study was conducted at the Department of Anesthesia, Analgesia and Intensive Care Medicine, Bangabandhu Sheikh Mujib Medical University (BSMMU), Dhaka, from January to March 2021. Patients aged more than 18 y with COVID-19 RTPCR positive attending in the Fever Clinic were recruited for this study. The study was approved by the Departmental Ethical Clearance Committee of and informed written consent was obtained from all the participants. The study participants were monitored in a remote monitoring platform at home and during hospital stay using online apps and/or telephone. The patients were provided with a pulse oximeter, patient information card including escalation warning signs and what to do in case of emergency. In addition to the standard management, patients were instructed to report their symptoms using the online apps and or dedicated telephone.

All patients were initially managed at home and HDU level beds were kept ready for admission, if and when necessary. If the patient was not digitally enabled, a healthcare professional registered the patient into the virtual platform. The registration process gathered all information such as oxygen saturation, heart rate, blood pressure, temperature, respiratory rate, and general health including symptoms experienced and any preexisting comorbid conditions. By using standardized data, the 'purpose built rules engine' triaged the patient to the recommended virtual ward and treatment pathway e.g. monitoring or medical treatment (Figure 1). 


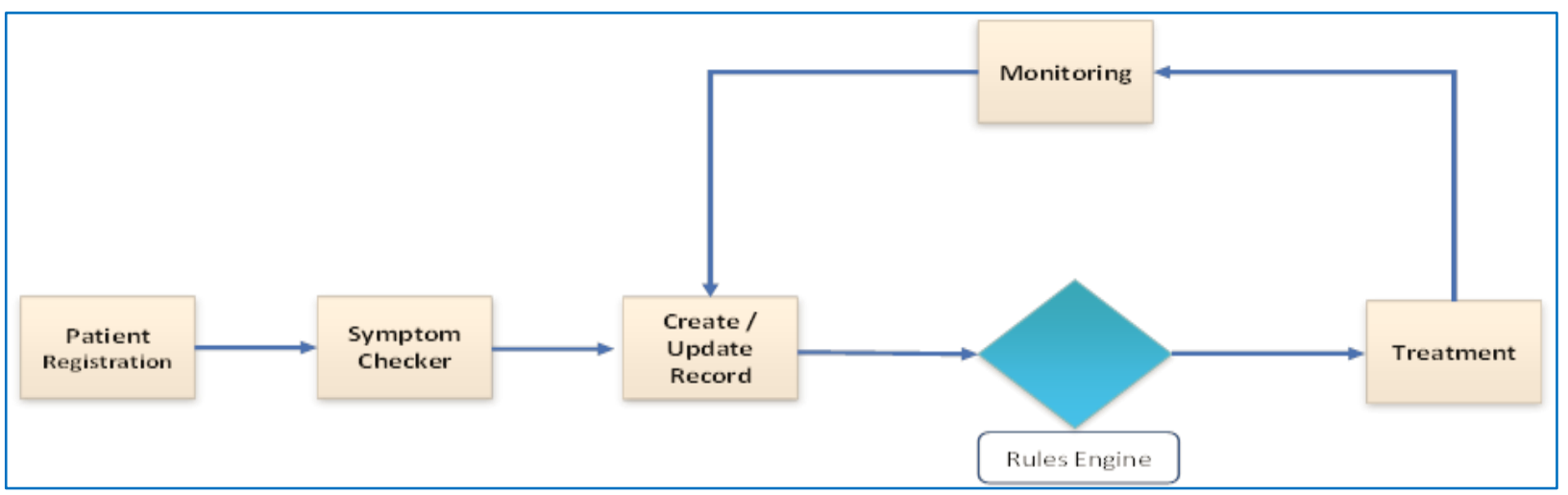

Figure 1: Remote monitoring pathway

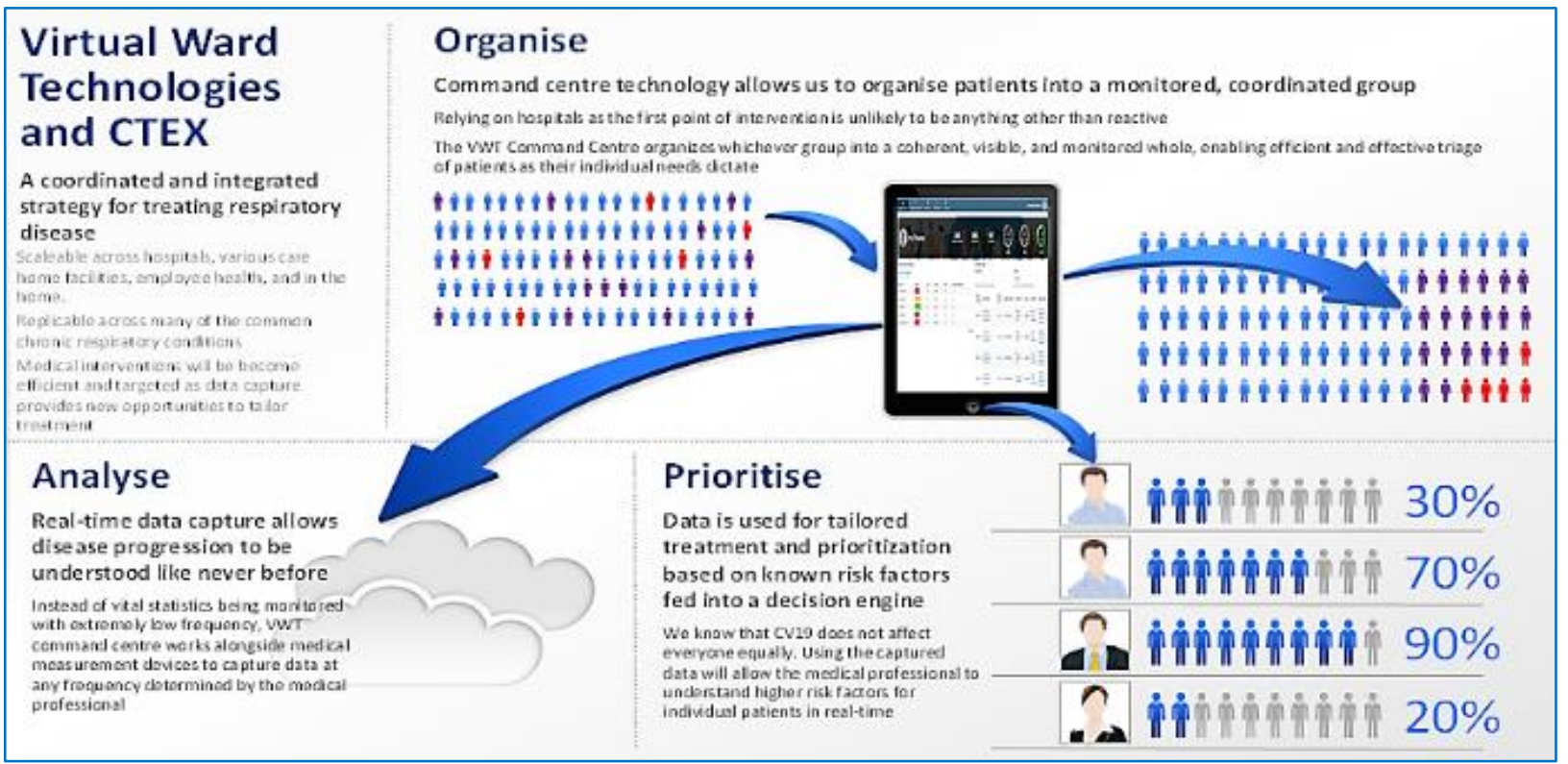

Figure 2: Virtual ward technologies monitoring system (with permission of the original copyright holder)

The patient record was continually updated (Figure 2) during treatment with regular flow of data from the patient or healthcare professional providing up to date information for the medical team (Clinical Trial Patient Registration Form - v0.7-1 (C) Virtual Ward Technologies). Updated information got re-run through the rules engine to ensure consistent and relevant application of patient pathways serving relevant information and context to the medical team at the right time. The patient received regular monitoring calls capturing changes in symptoms and trends in oxygen saturation.

The qualitative experience of the patients was documented by using a five points Likert scale (Box 1) within seven days after discharge from virtual platform or the hospital. The primary outcome measures of this study were the frequency of recovery (discharged from remote home monitoring) and escalation (admitted to hospital or ICU), and the discharge from hospital or

\section{Box 1: Five Points Likert Scale}

(a) Strongly agree (b) Agree (c) Neutral (d) Disagree (e) Strongly disagree

\section{Questionnaire}

1. You have been provided adequate information about home pulse oximetry and virtual ward technologies-

2. You have given necessary training to use the oximeter and virtual ward platform-

3. You have made contact regularly by an investigator over phone-

4. You have been assessed or evaluated adequately-

5. You have been given proper support and advice-

6. You have experienced delayed response from virtual ward support-

7. The whole process is complex-

8. You have felt reassured by virtual ward care-

9. You have satisfied with this virtual ward service-

10. This is an effective method of providing healthcare during this pandemic 
death. The secondary outcome measures included the length of hospital stay, patient experience and satisfaction and barriers associated with using this software.

Statistical Analysis: Continuous variables were expressed as mean \pm standard deviation or medians and ranges, depending on distribution. Categorical variables were presented as numbers and percentages over column total. Outcome measures (e.g. recovery, escalation, discharge or death) were figured in absolute frequencies, while frequency distributions were exercised to represent questionnaire data. All statistical analysis was carried out using Statistical Packages (SPSS) for Windows, version 23.0.

\section{Results}

A total of twenty confirmed COVID-19 patients from the capital city were recruited in this study, having male to female ratio of 1.8:1 and median age of $45 \mathrm{y}$ respectively. The average BMI was $27.21 \pm 2.82 \mathrm{Kg} / \mathrm{m}^{2}$. Most of the patients came from middle socioeconomic

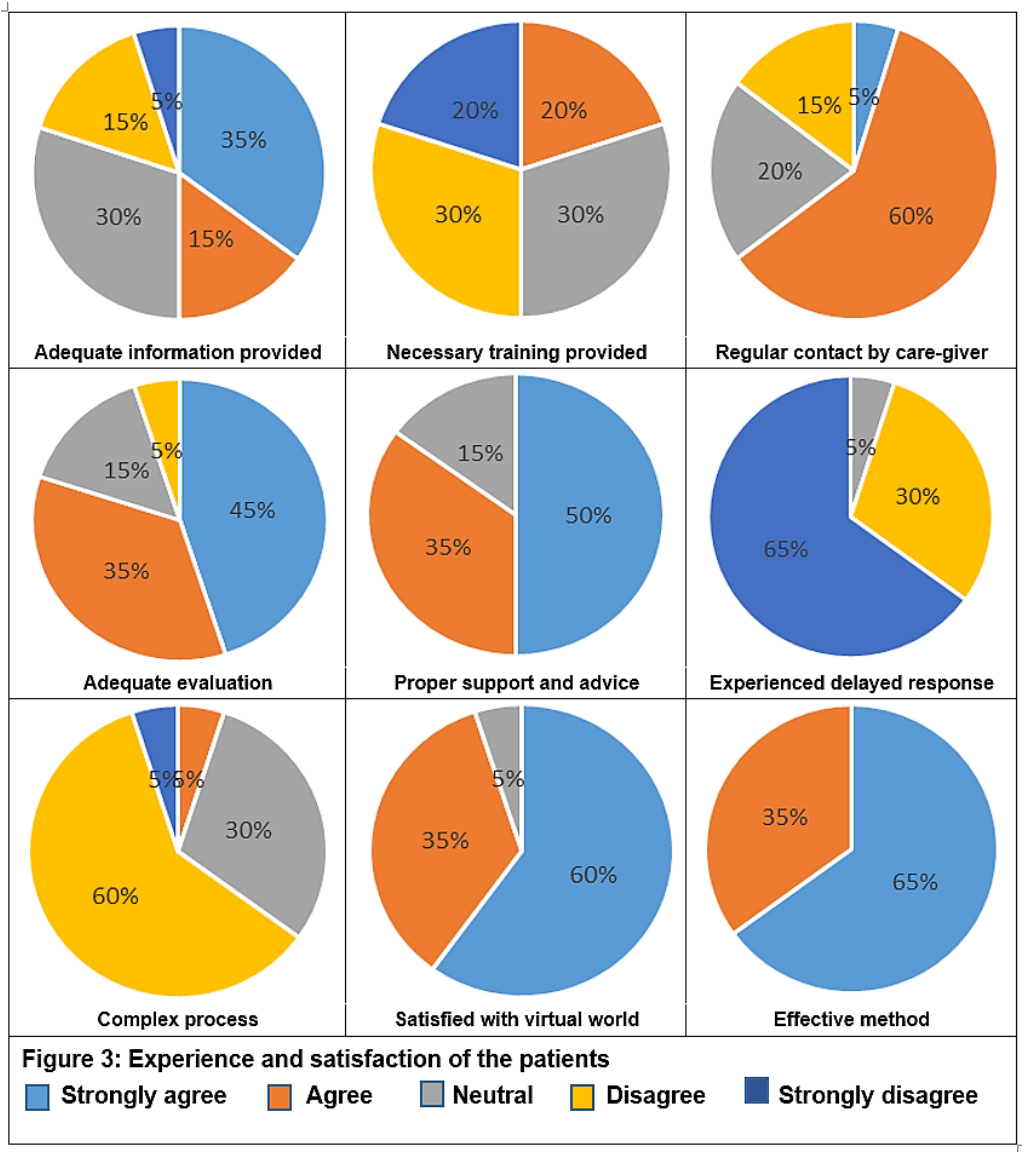

\begin{tabular}{|c|c|c|}
\hline \multicolumn{2}{|l|}{ Characteristics } & Value \\
\hline \multicolumn{2}{|l|}{ Age in years (Median) } & $45(36-55)$ \\
\hline \multirow{2}{*}{ Gender } & Male & $13(65 \%)$ \\
\hline & Female & $7(35 \%)$ \\
\hline \multicolumn{2}{|l|}{ BMI (Mean \pm SD) } & $27.21 \pm 2.82$ \\
\hline \multirow[t]{3}{*}{ Educational status } & Post-graduation & $6(30 \%)$ \\
\hline & Graduation & $12(60 \%)$ \\
\hline & Below graduation & $2(10 \%)$ \\
\hline \multirow[t]{3}{*}{ Occupational status } & Service holder & $12(60 \%)$ \\
\hline & Businessman & $5(25 \%)$ \\
\hline & Housewife & $3(15 \%)$ \\
\hline \multirow[t]{3}{*}{ Co-morbidities } & One & $9(45 \%)$ \\
\hline & Two & $7(35 \%)$ \\
\hline & More than two & $4(20 \%)$ \\
\hline \multirow[t]{3}{*}{ Severity of disease } & Mild & $11(55 \%)$ \\
\hline & Moderate & $7(35 \%)$ \\
\hline & Severe & $2(10 \%)$ \\
\hline \multicolumn{2}{|c|}{ Duration of monitoring in days } & $10(8-12)$ \\
\hline \multicolumn{2}{|c|}{ Hospitalization } & $3(15 \%)$ \\
\hline \multicolumn{2}{|c|}{ Duration of hospital stay in days } & $4(3-6)$ \\
\hline \multicolumn{2}{|l|}{ Discharge } & $20(100 \%)$ \\
\hline \multicolumn{3}{|c|}{$\begin{array}{l}\text { Values are presented as median, IQR and absolute number, within } \\
\text { parenthesis are percentage over column total. }\end{array}$} \\
\hline
\end{tabular}

background. Table 1 depicts demographic and clinical characteristics.

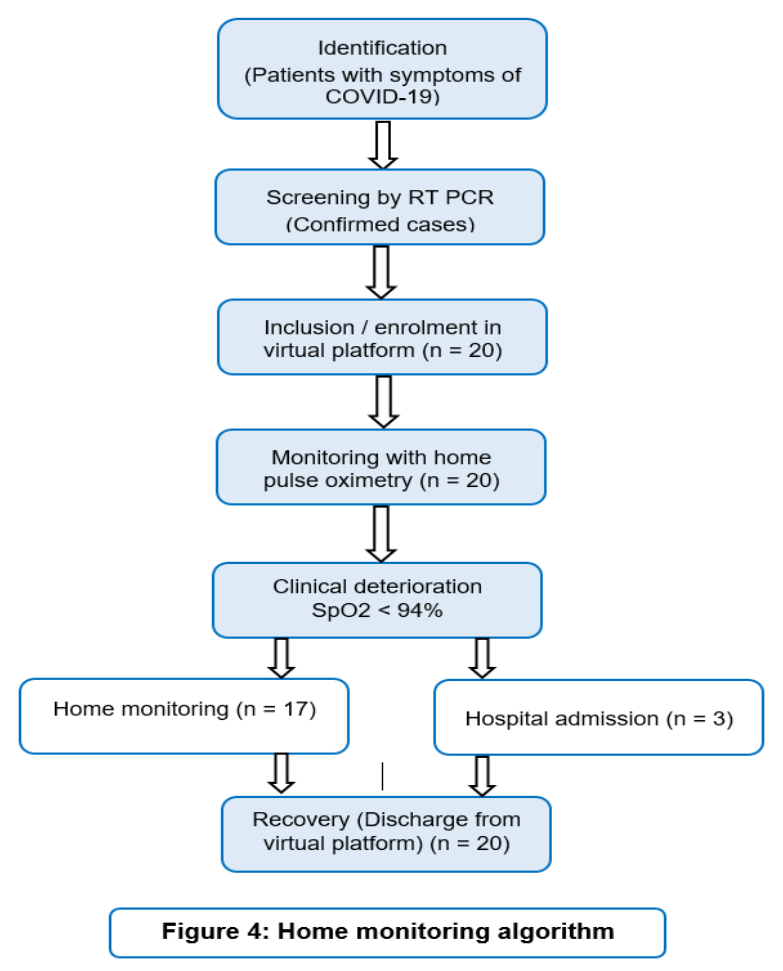




\begin{tabular}{|c|c|c|c|c|c|}
\hline $\begin{array}{l}\text { Patient } \\
\#\end{array}$ & Co-morbidities & $\begin{array}{l}\text { Days in } \\
\text { Hospital }\end{array}$ & Oxygen support & Other medications & Remarks \\
\hline $\begin{array}{l}\text { Patient } \\
01\end{array}$ & $\begin{array}{l}\text { Hypertension } \\
\text { with Ischemic } \\
\text { Heart Disease }\end{array}$ & 3 & $\begin{array}{l}3 \mathrm{~L} / \mathrm{min} \text { through } \\
\text { nasal prong }\end{array}$ & $\begin{array}{l}\text { Remdesivir IV } \\
\text { Dexamethasone IV } \\
\text { Enoxaparin SC }\end{array}$ & Discharged \\
\hline $\begin{array}{l}\text { Patient } \\
02\end{array}$ & $\begin{array}{l}\text { Hypertension, } \\
\text { Diabetes and one } \\
\text { bout of epistaxis }\end{array}$ & 3 & Ambient air & Remdesivir IV & Discharged \\
\hline $\begin{array}{l}\text { Patient } \\
03\end{array}$ & $\begin{array}{l}\text { Hypertension with } \\
\text { Ischemic Heart } \\
\text { Disease, } \\
\text { Obesity }\end{array}$ & 6 & $\begin{array}{l}\mathrm{HFNC} \\
60 \mathrm{~L} / \mathrm{min} \\
\mathrm{FiO}_{2} 0.8\end{array}$ & $\begin{array}{l}\text { Remdesivir IV } \\
\text { Dexamethasone IV } \\
\text { Enoxaparin SC }\end{array}$ & Discharged \\
\hline
\end{tabular}

Out of twenty, 9 (45\%) patients had co-morbidities like hypertension, DM, IHD, COPD/BA, CKD. Patients were monitored for $10(8-12)$ days. Most of the patients had mild symptomatic COVID-19. Only three (10\%)

patients deteriorated and all of them had more than two systemic illness along with COVID-19. The average of the last $\mathrm{SpO}_{2}$ values before hospitalization was $90.0 \pm$ $1.0 \%$. The median duration of hospital stay was 4 (3-6) days, and none of them required ICU admission (Table 2). All patients were discharged from remote monitoring and no death was reported.

Within seven days after discharge from monitoring platform or the hospital, patients were interviewed by means of a questionnaire on their experience and satisfaction, shown in Figure 3.

Thirty-five percent respondents strongly agreed that they had been provided adequate information about virtual ward technologies. Among participants, 65\% reported of being regularly contacted and $80 \%$ replied that they were evaluated adequately. Fifty percent strongly agreed about proper support

and advice was given. Small proportion of patients experienced delayed response from virtual ward service. Majority of the respondents were reassured (95\%) and satisfied $(95 \%)$ by this platform. Sixty percent of patients disagreed about the complexity of this process and $65 \%$ strongly recommended as an effective method of providing healthcare during the pandemic.

\section{Discussion}

We are passing through a COVID-19 era where the novel virus has transformed the whole of the world. Limited resources, scarcity of trained personnel and lack of adequate policies to tackle the pandemic overstretched our healthcare infrastructures. Inaccessibility to timely needed adequate medical care for all patients posed great challenges. So far, this is the very first study in
Bangladesh to monitor patients with COVID-19 remotely at home with prompt recognition of deteriorating condition and keep necessary arrangements for immediate hospitalization. Remote monitoring of COVID-19 patients is feasible with this virtual platform (Figure 4).

In this study, all the necessary data were collected with sufficient quality and safely transferred to the virtual platform for evaluation and management. Continuously monitoring and evaluation of home bound patients were performed by one of the team members, followed by implementation of necessary measures done over phone. Adapting virtual technology to provide optimum medical care in such pandemic became fruitful.

The normal range of oxygen saturation is $94-98 \%$ at rest in patients without chronic lung disease and $88 \%-92 \%$ in patients with chronic lung disease. ${ }^{22} \mathrm{~A}$ drop in saturation of $3 \%$ or more on exertion is considered abnormal where drop of $4 \%$ or more may need hospital admission. ${ }^{6}$ Various kinds of remote monitoring services have been introduced using different approaches, including online platforms, paper based systems withtelephone calls, or through wearable sensors. ${ }^{6,23}$ Remote monitoring by phone and paper tended to achieve lower data capture than electronic ones (apps, web portals, or wearable sensors) but also appeared to be more inclusive. It has been found that about 1737 patients were referred for virtual ward care across six UK centers, out of which only 20 deaths occurred $(1.1 \%) .{ }^{24,25}$

Use of digital technologies to obtain patients data including oxygen saturation levels following monitoring and electronically transferred information to healthcare provider in various parts of the world has been documented. ${ }^{26-28}$

Hospitalized patients under the trail had co-morbidities along with COVID-19 pneumonia. Deterioration of their clinical conditions once met the admission criteria, was 
dealt with prudency using this technology. None of them required ventilator support and all were discharged home. This result was supported by a study done by Islam et al. 2021. ${ }^{14}$ Another study involving home monitoring with pulse oximeter revealed that $23 \%$ patients who were followed up with remote monitoring system were timely admitted at hospitals and given necessary management. ${ }^{29}$

Majority of our patients were very satisfied with this telemedicine technology, felt reassured and comfortable. Most of the respondents reported that this was an effective method of patient management during this pandemic. Such service can help to reduce the unnecessary hospitalization and relieve the burden on healthcare system particularly in low and lower-middle income countries.

We think that remote home monitoring has a positive economic impact by reducing hospitalization, length of hospital stay, intensive care support, and cost minimization. According to Bangladesh Telecommunication regulatory report total mobile phone users are 162, 930 million. Among them 101,186 million are internet subscribers. About $74 \%$ population aged $15-$ $75 \mathrm{y}$ in Bangladesh use mobile phone. So, high percentage of population can be evaluated under the umbrella of virtual care. ${ }^{30}$

\section{Limitations}

The current study was done on a small scale and sometimes mobile network or internet services were interrupted, leading to delay in data transmission. Further studies including larger sample size and comparators are needed to determine the superiority and costeffectiveness of the telemedicine service.

\section{Acknowledgements}

We gratefully acknowledge Dr Rhys Thomas and Virtual Ward Technologies for providing access to their database for storing data of COVID-19 patients for this trial.

\section{Conflicting interests}

The authors have no conflicts of interest to declare. No external or internal funds were received for this study.

\section{Authors' contribution:}

AKMA- Concept, protocol preparation, manuscript writing and final edit.

MMK, MP - Manuscript writing, data compiling and analysis

MR, RD - Data collection, compiling and help to write up manuscript
MSI, DKB - Manuscript writing, data analysis and initial editing

\section{References}

1. Hu Z, Song C, Xu C, Jin G, Chen Y, Xu X, et al. Clinical characteristics of 24 asymptomatic infections with COVID-19 screened among close contacts in Nanjing, China. Sci China Life Sci. 2020 May;63(5):706-711. [PubMed] DOI: 10.1007/s11427020-1661-4

2. World Health Organization. General's Opening Remarks at the Media Briefing on COVID-19; 2020. Available from: https://www.who.int/director-general/speeches/detail/whodirector-general-s-opening-remarks-at-the-media-briefing-oncovid-19---11-march-2020

3. Vaishya R, Javaid M, Khan $\mathrm{H}$, Haleem A. Artificial Intelligence (AI) applications for COVID-19 pandemic. Diabetes Metab Syndr. 2020 Jul-Aug;14(4):337-339. [PubMed] DOI: 10.1016/j.dsx.2020.04.012

4. World Health Organization. COVID-19 strategy update; 2020. Available from: https://www.who.int/publications/m/item/covid19-strategy-update

5. Worldometers. Coronavirus cases; 2021. Available from: https://www.worldometers.info/coronavirus/

6. Greenhalgh T, Knight M, Inda-Kim M, Fulop NJ, Leach J, Vindrola-Padros C. Remote management of covid-19 using home pulse oximetry and virtual ward support. BMJ. 2021 Mar 25;372:n677. [PubMed] DOI: 10.1136/bmj.n677

7. Santus $P$, Radovanovic D, Saderi L, Marino P, Cogliati C, Rizzi $M$, et al. Severity of respiratory failure at admission and inhospital mortality in patients with COVID-19: a prospective observational multicentre study. BMJ Open. 2020;10:e043651. [PubMed] DOI: 10.1136/bmjopen-2020-043651

8. Couzin-Frankel J. The mystery of the pandemic's 'happy hypoxia'. Science. 2020;368(6490):455-6. [PubMed] DOI: 10.1126/science.368.6490.455

9. Richardson S, Hirsch JS, Narasimhan M, Barnaby DP, Becker LB, Cohen SL, et al. Presenting characteristics, comorbidities, and outcomes among 5700 patients hospitalized with COVID-19 in the New York City area. JAMA. 2020;323:2052-9. [PubMed] DOI: 10.1001/jama.2020.6775

10. Mansab F, Donnelly H, Kussner A, Neil J, Bhatti S, Goyal DK. Oxygen and mortality in covid-19 pneumonia: a comparative analysis of supplemental oxygen policies and health outcomes across 26 countries. Front Public Health. 2021 Jul 13;9:580585. [PubMed] DOI: 10.3389/fpubh.2021.580585

11. WHO Bangladesh, WHO Bangladesh COVID-19 Morbidity and Mortality Weekly Update (MMWU); 2020. Available from: https://cdn.who.int/media/docs/default-

source/searo/bangladesh/covid-19-who-bangladesh-situationreports/who_covid-19update_39_20201123.pdf?sfvrsn=ebe679c6_11

12. World Health Organization, Global Health Workforce Alliance. Available https://www.who.int/workforcealliance/countries/bgd/en/

13. Mostafa N. Critical care medicine: Bangladesh perspective. Adv J Emerg Med. 2018 Jan 9;2(3):e27. [PubMed] DOI: 10.22114/AJEM.v0i0.79 
14. Islam MS, Bhowmick DK, Parveen M, Kamal MM, Akhtaruzzaman AK. Case fatality rate and survival functions of severe COVID-19 patients in intensive care unit of Bangabandhu Sheikh Mujib Medical University in Bangladesh: an observational study. Anaesth Pain Intensive Care. 2021 Aug 3;25(4):443-9. [FreeFullText] DOI: 10.35975/apic.v25i4.1553

15. Mbunge E, Akinnuwesi B, Fashoto SG, Metfula AS, Mashwama P. A critical review of emerging technologies for tackling COVID19 pandemic. Hum Behav Emerg Tech. 2021;3:25-39. [PubMed] DOI: 10.1002/hbe2.237

16. VIRTUAL WARD TECHNOLOGIES LIMITED. Available from: https://www.dnb.com/business-directory/companyprofiles.virtual_ward_technologies_limited.fb15f92d5e36ddb1a 4ab2e547683107d.html

17. Abdel-Basset $M$, Chang $V$, Nabeeh NA. An intelligent framework using disruptive technologies for COVID-19 analysis. Technol Forecast Soc Change. 2021;163:120431. [PubMed] DOI: 10.1016/j.techfore.2020.120431

18. Vaishya $R$, Javaid M, Khan $I H$, Vaish A, lyengar KP. Significant role of modern technologies for COVID-19 pandemic. J Industrial Integration Manag. 2021;6(2):147-159. DOI: 10.1142/S242486222150010X

19. Vindrola-Padros C, Singh KE, Sidhu MS, Georghiou T, SherlawJohnson C, Tomini SM, et al. Remote home monitoring (virtual wards) during the covid-19 pandemic: a living systematic review. MedRxiv. 2020;20208587. DOI: 10.1101/2020.10.07.20208587

20. NHS. Pulse oximetry to detect early deterioration of patients with COVID-19 in primary and community care settings. NHS; 2020. Available https://www.england.nhs.uk/coronavirus/publication/pulseoximetry-to-detect-early-deterioration-of-patients-with-covid-19in-primary-and-community-care-settings/

21. World Health Organization. Covid-19 clinical management: living guideline (updated 25.1.21); 2021. Available from: https://apps.who.int/iris/handle/10665/338882

22. O'Driscoll BR, Howard LS, Earis J, Mak V. BTS guideline for oxygen use in adults in healthcare and emergency settings.
Thorax. 2017;72(Suppl 1):ii1-90. [PubMed] DOI: 10.1136/thoraxjnl-2016-209729

23. Quer G, Radin JM, Gadaleta M, Baca-Motes K, Ariniello L, Ramos E, et al. Wearable sensor data and self-reported symptoms for COVID-19 detection. Nat Med. 2021;27:73-77. [PubMed] DOI: 10.1038/s41591-020-1123-X

24. Vindrola-Pados C, Sidhu MS, Georghiou T, Sherlaw-Johnson C, Tomini SM, Singh KE, et al. The implementation of remote home monitoring models during the COVID-19 pandemic in England. EClinicalMedicine. 2021;34:100799. [PubMed] DOI: 10.1016/j.eclinm.2021.100799

25. Francis NA, Stuart B, Knight M, Vancheeswaran R, Oliver C, Willcox $\mathrm{M}$, et al. Predictors of adverse outcome in patients with suspected covid-19 managed in a "virtual hospital" setting: a cohort study. BMJ Open. 2021;11(3):e045356. [PubMed] DOI: 10.1136/bmjopen-2020-045356

26. Margolius D, Hennekes M, Yao J, Einstadter D, Gunzler D, Chehade $\mathrm{N}$, et al. On the front (phone) lines: results of a covid19 hotline. J Am Board Fam Med. 2021 Feb;34(Suppl):S95S102. [PubMed] DOI: 10.3122/jabfm.2021.S1.200237

27. Hutchings $O$, Dearing $C$, Jagers $D$, Shaw M, Raffan F, Jones $A$, et al. Virtual health care for community management of patients with COVID-19. medRxiv 2020:2020.05.11.20082396. DOI: 10.1101/2020.05.11.20082396

28. Annis T, Pleasants S, Hultman G, Lindemann E, Thompson JA, Billecke S, et al. Rapid implementation of a COVID-19 remote patient monitoring program. J Am Med Inform Assoc. 2020;27(8):1326-1330. [PubMed] DOI: 10.1093/jamia/ocaa097

29. Gootenberg DB, Kurtzman N, O'Mara T, Ge JY, Chiu D, Shapiro $\mathrm{NI}$, et al. Developing a pulse oximetry home monitoring protocol for patients suspected with COVID-19 after emergency department discharge. BMJ Health Care Inform. 2021 Jul;28(1):e100330. [PubMed] DOI: 10.1136/bmjhci-2021100330

30. Mobile Phone Subscribers in Bangladesh. BTRC; 2020 Apr. Available from: http://www.btrc.gov.bd/content/mobilephone-subscribers-bangladesh-april-2020 